ISSN 1422-8599

www.mdpi.com/journal/molbank

Short Note

\title{
(Benzoylamino)methyl 4-[(Benzoylamino)methoxy]benzoate
}

\section{Emil Popovski $^{1, *}$, Kristina Mladenovska ${ }^{2}$ and Ana Poceva Panovska ${ }^{2}$}

1 Institute of Chemistry, Faculty of Natural Sciences \& Mathematics, Ss. Cyril and Methodius University, Arhimedova 5, PO Box 162, 1000 Skopje, Macedonia

2 Department of Drug Design and Metabolism, Faculty of Pharmacy, Ss. Cyril and Methodious University, Vodnjanska 17, 1000 Skopje, Macedonia

* Author to whom correspondence should be addressed; E-Mail: popovski.emil@gmail.com.

Received: 1 December 2010 / Accepted: 21 December 2010 / Published: 24 December 2010

\begin{abstract}
In this note, two procedures for the synthesis of (benzoylamino)methyl 4-[(benzoylamino)methoxy]benzoate (3) are presented. The first procedure is carried out in dioxane/water using benzoylaminomethyl-4-hydroxybenzoate, while the second one employs a suspension of 4-hydroxybenzoic acid in dioxane. In both procedures, benzamidomethyl triethylammonium chloride is used for the benzamidomethylation reaction.
\end{abstract}

Keywords: benzamidomethyl ester; synthesis

Methyl 4-methoxybenzoate (also known as methyl anisate) is a white crystalline powder, soluble in alcohol and ether, but insoluble in water. In the nature, it occurs as a volatile compound in mushroom species and plants [1-5]. These types of esters are used as pharmaceutical intermediates and take part in many organic syntheses [6,7]. For example, a new imaging compound, [(125)I]iodoDPA-713, was synthesized in several steps from methyl 4-methoxybenzoate as a tool for quantification of inflammation in preclinical models [6]. Nowadays, methyl 4-methoxybenzoate has application in the flavor and perfume industry as synthetic flavoring substance due to its sweet herbal anis aroma, impressing lilac or magnolia $[8,9]$.

In this note, the synthesis of a new compound, (benzoylamino)methyl 4-[(benzoylamino)methoxy]benzoate (3), similar to methyl anisate, is reported. The synthesis of $\mathbf{3}$ was carried out by using (benzamidomethyl)triethylammonium chloride (2) as a reagent for benzamidomethylation. Although 2 is an excellent reagent for benzamidomethylation of phenols [10], in our previous work [11] we demonstrated that the phenol group at 4-hydroxybenzoic acid (4) cannot be benzamidomethylated with 
2 in aqueous media. The carboxylic group as a weak nucleophile in aqueous media does not react [12], but it deactivates the phenol group in the molecule of 4-hydroxybenzoic acid. However, once the carboxylic group is protected as in (benzoylamino)methyl 4-hydroxybenzoate (1), the hydroxyl group can be easily benzamidomethylated with 2 in aqueous media to obtain 3 (Scheme 1).

As presented in Scheme 1, the title compound can also be obtained directly from $\mathbf{4}$ in dioxane suspension of 2 at $50{ }^{\circ} \mathrm{C}$.

Scheme 1. Synthetic routes to the title compound 3.

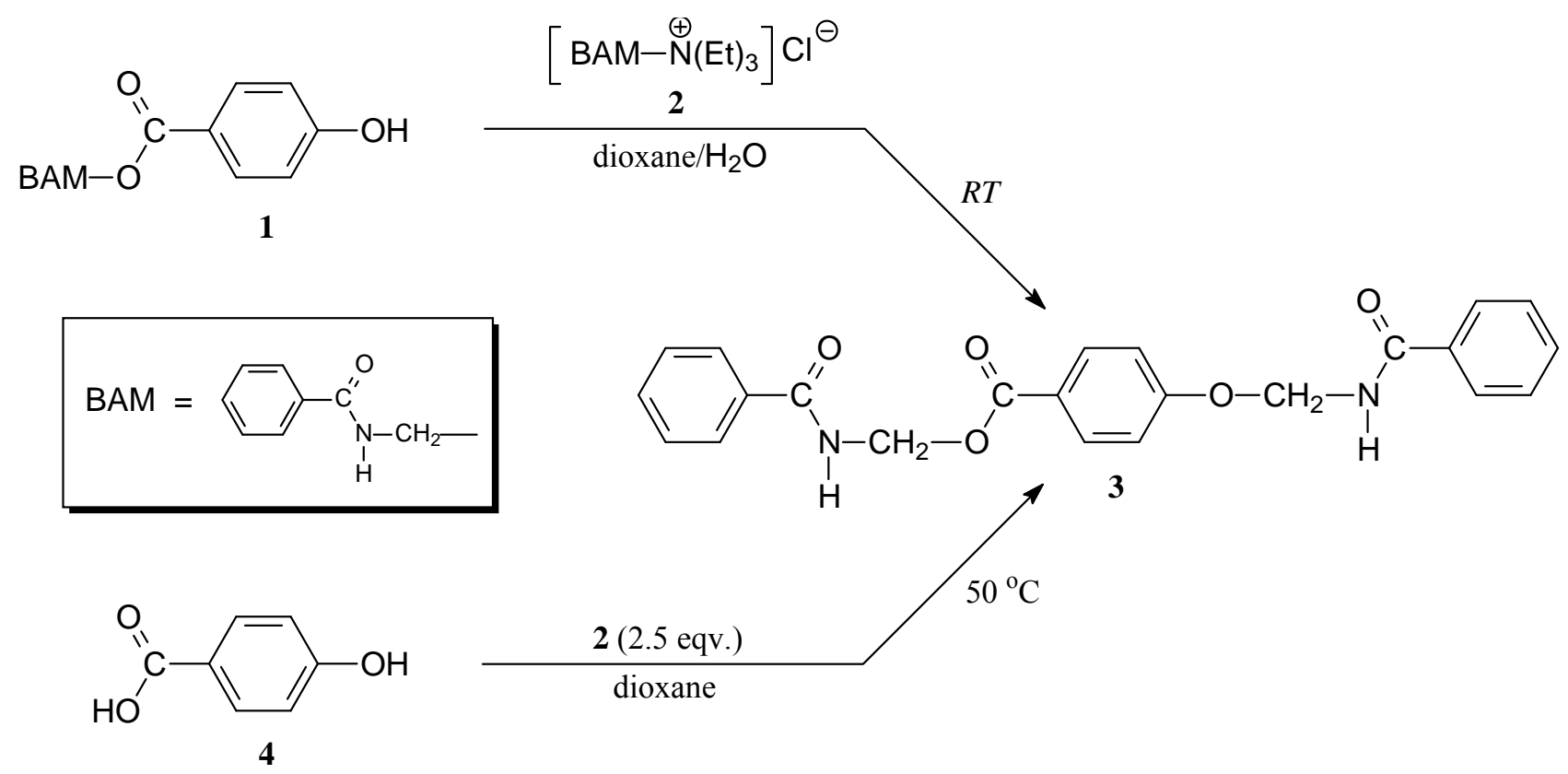

\section{Experimental}

Compound $\mathbf{2}$ is not commercially available and it was synthesized as described previously [10].

(Benzoylamino)methyl 4-[(benzoylamino)methoxy]benzoate (3)

Procedure A

To a mixture of $1(0.310 \mathrm{~g}, 1.14 \mathrm{mmol})$, well powdered $2(0.334 \mathrm{~g}, 1.23 \mathrm{mmol})$, dioxane $(25 \mathrm{~mL})$ and triethylamine $(0.1 \mathrm{~mL})$ was added water drop by drop, until a clear solution was obtained. The mixture was stirred for $10 \mathrm{~h}$ at room temperature and subsequently water was added until occurrence of a precipitate. The maximal yield of crude colorless crystals was $70 \%$. The purification was performed firstly by dissolving the product in dioxane and by precipitation with water and then by recrystallization from ethyl acetate.

Procedure B

To a suspension of $2(0.529 \mathrm{~g}, 1.95 \mathrm{mmol})$ in dioxane $(10 \mathrm{~mL})$ were added $4(0.108 \mathrm{~g}, 0.78 \mathrm{mmol})$ and TEA $(0.1 \mathrm{~mL})$. The mixture was stirred and heated at $50{ }^{\circ} \mathrm{C}$ for $24 \mathrm{~h}$. After cooling, water was 
added until a white precipitate occurred. The colorless crystals were filtered off and purified as described in Procedure A. Maximum yield was 56\%.

Melting point of pure crystals: $176.5-177.5^{\circ} \mathrm{C}$ (uncorrected).

FT-IR (KBr): 3,311 (vNH), 1,728 (vOC=O), 1,655 (Amide I), 1,536 cm $\mathrm{cm}^{-1}$ (Amide II).

${ }^{1} \mathrm{H}-\mathrm{NMR}\left(250 \mathrm{MHz}, \mathrm{DMSO}-d_{6}\right): \delta / \mathrm{ppm} 9.62(\mathrm{t}, J=6.7 \mathrm{~Hz}, 2 \mathrm{H}, 2 \mathrm{xNH}) ; 7.95-7.15(14 \mathrm{H}, \mathrm{Ar}) ; 5.57$ (d, $\left.J=6.7 \mathrm{~Hz}, 2 \mathrm{H}, \mathrm{N}-\mathrm{CH}_{2}-\mathrm{O}\right) ; 5.40\left(\mathrm{~d}, J=6.7 \mathrm{~Hz}, 2 \mathrm{H}, \mathrm{N}-\mathrm{CH}_{2}-\mathrm{O}\right)$

${ }^{13} \mathrm{C}-\mathrm{NMR}\left(63 \mathrm{MHz}, \mathrm{DMSO}-d_{6}\right): \delta / \mathrm{ppm} 167.1(\mathrm{C}=\mathrm{O}) ; 167.0(\mathrm{C}=\mathrm{O}) ; 68.7\left(\mathrm{CH}_{2}\right) ; 65.5\left(\mathrm{CH}_{2}\right) ; \mathrm{Ar}: 161.0$, $133.3,133.2,132.1,131.4,128.5,127.6,127.5,122.2,115.3$.

Anal. Calcd. (found) for $\mathrm{C}_{23} \mathrm{H}_{20} \mathrm{~N}_{2} \mathrm{O}_{5}$ : C, 68.31 (68.13); H, 4.98 (5.19); N, 6.93 (6.85).

\section{References}

1. Rapior, S.; Breheret, S.; Talou, T.; Pélissier, Y.; Bessière, J.-M. The anise-like odor of Clitocybe odora, Lentinellus cochleatus and Agaricus essettei. Mycologia 2002, 94, 373-376.

2. Binder, R.G.; Flath, R.A. Volatile components of pineapple guava. J. Agric. Food Chem. 1989, 37, 734-736.

3. Hardy, P.J.; Michael, B.J. Volatile components of feijoa fruits. Phytochemistry 1970, 9, 1355-1357.

4. Shaw, G.J.; Ellingham, P.J.; Birch, E.J. Volatile constituents of feijoa-headspace analysis of intact fruit. J. Sci. Food Agr. 1983, 34, 743-747.

5. Ceballos, L.; Pino, J.A.; Quijano-Celis, C.E.; Dago A. Optimization of a HS-SPME/GC-MS Method for determination of volatile compounds in some Cuban unifloral honeys. J. Food Quality 2010, 33, 507-528.

6. Wang, H.; Pullambhatla, M; Guilarte, T.R.; Mease, R.C.; Pomper, M.G.; Synthesis of [125I]iodoDPA-713: A new probe for imaging inflammation. Biochem. Biophys. Res. Commun. 2009, 389, 80-83.

7. Chandra, B.K.; Ramadasu, G.; Gangaiah, L.; Madhusudhan, G.; Mukkanti, K. A new route for the synthesis of (R)-glyceraldehyde acetonide: A key chiral building block. Indian J. Chem. B 2010, 49, 260-263.

8. Perriot, R., Breme, K., Meierhenrich, U.J., Carenini, E., Ferrando, G., Baldovini, N. Chemical composition of French mimosa absolute oil. J. Agric. Food Chem. 2010, 58, 1844-1849.

9. Panda, H. Perfumes and flavours technology handbook; Asia Pacific Business Press Inc: Delhi, India, 2010.

10. Popovski, E.; Klisarova, L.; Vikic-Topic, D. Simple method for benzamidomethylation of phenols in water solution. Synth. Commun. 1999, 29, 3451-3458.

11. Popovski, E.; Mladenovska, K. (Benzoylamino)methyl 4-hydroxybenzoate. Molbank 2010, 2010, M658. 
12. Popovski, E.; Klisarova, L.; Vikic-Topic, D. Benzamidomethylation with (benzamidomethyl)triethylammonium chloride 2. A simple method for benzamidomethylation of thiols, amines and carboxylic acids. Molecules 2000, 5, 927-936.

(C) 2010 by the authors; licensee MDPI, Basel, Switzerland. This article is an open access article distributed under the terms and conditions of the Creative Commons Attribution license (http://creativecommons.org/licenses/by/3.0/). 